\title{
Three-dimensional numerical simulations on wind- and tide-induced currents: The case of Augusta Harbour (Italy)
}

\author{
Mauro De Marchis ${ }^{\mathrm{a}, *}$, Gabriele Freni ${ }^{\mathrm{a}}$, Enrico Napoli ${ }^{\mathrm{b}}$ \\ ${ }^{a}$ Facoltà di Ingegneria e Architettura, Università di Enna Kore, Cittadella Universitaria, Enna 94100, Italy \\ ${ }^{\mathrm{b}}$ Dipartimento di Ingegneria Civile, Ambientale, Aerospaziale e dei Materiali, Università di Palermo, Viale delle scienze, Palermo 90128, Italy
}

\section{A R T I C L E I N F O}

\section{Article history:}

Received 15 December 2013

Received in revised form

1 July 2014

Accepted 2 July 2014

Available online 11 July 2014

Keywords:

Wind-driven flow

MPI

3D hydrodynamic model

Finite volume model

Parallel computing

\begin{abstract}
A B S T R A C T
The hydrodynamic circulation in the coastal area of the Augusta Bay (Italy), located in the eastern part of Sicily, is analysed. Due to the heavy contamination generated by the several chemical and petrochemical industries active in the zone, the harbour was declared a Contaminated Site of National Interest. To mitigate the risks connected with the industrial activities located near the harbour, it is important to analyse the hydrodynamic circulation in the coastal area. To perform such analysis, a parallel 3D numerical model is used to solve the Reynolds-averaged momentum and mass balance, employing the $k-\varepsilon$ turbulence model for the Reynolds stresses. The numerical model is parallelized using the programing technology - Message Passing Interface (MPI) and applying the domain decomposition procedure.

The Augusta Bay circulation is mainly due to the relative contribution of the wind force acting over the free surface and the tidal motion through the mouths. Due to the geometric complexity of the domain and the presence of several piers along the coast, a curvilinear boundary-fitted computational grid was used, where cells corresponding to land areas or to wharfs were excluded from the computation. Comparisons between numerical results and field measurements were performed. Three different simulations were performed to selectively isolate the effect of each force, wind and tide, acting in the considered domain. The current in the basin was successfully estimated on the basis of the numerical results, demonstrating the specific role of wind and tidal oscillation in the hydrodynamic circulation inside the harbour.
\end{abstract}

(c) 2014 Elsevier Ltd. All rights reserved.

\section{Introduction}

The preservation of coastal areas has become a significant issue due to increasing anthropogenic pressure and the expansion of urban areas. Rivers, lakes and seas were the natural receptacles of raw urban waste for a long time. This practice, which is scarcely sustainable, has led to increased research interest in the analysis of the hydrodynamics of environmental water bodies (De Marchis et al., 2013). In such fields, the hydrodynamic circulation is mainly driven and influenced by several elements, including bathymetry, tidal oscillations, wind fields or density gradient. The last contribution assumes a significant impact when large freshwater inflow or thermal differences occur in the region (van Rijn Leo, 2011). To selectively investigate the relative contributions among these elements, several experimental observations and numerical simulations (see De Marchis et al., 2012 and literature cited therein) have been performed in coastal lagoons.

\footnotetext{
*Corresponding author. Tel.: +39 0935 536438; fax: +390935 536962.

E-mail address: mauro.demarchis@unikore.it (M. De Marchis).
}

Coastal waters are often shallow, so two-dimensional water numerical models have been extensively developed, especially considering that one of the main attraction of $2 \mathrm{D}$ models is the computational economy they provide. Different 2D hydrodynamic models (see among others Suursaar et al., 2002; Umgiesser et al., 2004; Krámer and Józsa, 2004) were used to simulate the effect of the forces acting on the water bodies. Vethamony et al. (2005) and Babu et al. (2005) employed a calibrated 2D shallow water numerical model to predict the tides and tidal currents in the Gulf of Kachchh (India), highlighting the importance of analysing the relative effects of the acting forces. In order to investigate the effects of wind and water level variation forces on the circulation of coastal lagoons, Ferrarin and Umgiesser (2005) and Niedda and Greppi (2007) applied 2D numerical models. The former, focusing on the hydrodynamics in the Cabras lagoon (Italy), showed that wind is the main force responsible for the circulation, while the water level variation modulates the discharges through the mouth. The latter, analysing the hydrodynamics in the Calich lagoon in the Sardinia (Italy) Sea, noted that a balance of tidal, atmospheric and seiche forces drive the circulation.

More recently, a 3D numerical model was used by Balas and Ozhan (2002) to perform simulation in the Göksu Lagoon (Turkey). 
They found that the current is mainly driven by wind and that even if the water depth is quite shallow, some recirculation phenomena in the vertical plane can be found. For this reason, they stated that 3D numerical models seem preferable in any case to 2D simplifications, despite the computational costs. Later, Grifoll et al. (2009) studied the hydrodynamic conditions within the Bilbao Harbour (Spain) by means of 3D numerical simulation. The authors found that the circulation pattern is affected by tide, wind and the presence of freshwater. The need to account for both wind and tidal forces in coastal waters was also demonstrated by MacCready et al. (2009) in their study of the Columbia River estuary (USA). The attention to Mediterranean lagoons is confirmed by the analysis of Umgiesser et al. (2014) where a comparison study between 10 Mediterranean lagoons has been carried out by means of the 3D numerical model.

Recently, De Marchis et al. (2012) demonstrated the importance of investigating the relative contributions of the different forces that affect hydrodynamics by reproducing the circulation in the Stagnone di Marsala lagoon, located in the northwestern part of Sicily (Italy). The authors found that, due to the shallowness of the water body, the wind generates wide recirculation regions below the free surface, increasing water mixing. In that case the authors investigated the hydrodynamic flow field in a very shallow lagoon, with a mean depth of about $1 \mathrm{~m}$ and observed that the tide plays a key role inducing the current in the north direction.

The impact of wind and tide in the hydrodynamic analysis of coastal areas is seen as a major problem (Caviglia and Dragani, 1996; Sankaranarayanan, 2007), unfortunately, in the literature there are few examples of the estimation of the contribution of each driving force in the formation of local circulation patterns.

The present paper deals with the parallel numerical simulation of the impact of wind and tidal driving forces on the hydrodynamic circulation in a harbour area. This is a major critical point in the above-cited literature. The study will be applied to the Augusta Harbour, which, because of the intense petrochemical industries operating since 1954 , is one of the most contaminated Italian coastal sites (Orecchio and Polizzotto, 2013; Di Bella et al., 2013).

\section{Materials and methods}

\subsection{Study area}

The Augusta Harbour, located at the eastern coast of Sicily (Italy), is one of Italy's most densely industrialised sites. Many chemical and petrochemical industries have operated in this coastal area in the last few decades, with heavy environmental consequences, especially in the water body (Di Bella et al., 2013). The harbour, shown in Fig. 1, is connected to the open sea through the southern and eastern mouths. The two entrances, both approximately $400 \mathrm{~m}$ wide, are characterised by a water depth of about $40 \mathrm{~m}$ and $20 \mathrm{~m}$ for the eastern and southern mouth, respectively, and ensure the transport of mass and water mixing with the open sea. The area is approximately $24 \mathrm{~km}^{2}$. The harbour extends approximately $8.0 \mathrm{~km}$ in the north direction and $4 \mathrm{~km}$ in the east direction, and its average depth is approximately $15.0 \mathrm{~m}$ (see Fig. 1). A series of piers are located along the western coast and mainly sand and fine sediments cover the bottom.

Several small rivers drain into the water body. The effect of the fresh water into the receiving water body should be mainly responsible for density-induced currents. These currents, in the region located close to the coastal zone and the estuary, are related to spatial density gradients due to variations of the salinity and temperature (see, van Rijn Leo, 2011). In the present case, due to the seasonal and discontinuous freshwater discharges, the contributions of these rivers are neglected.

Although it is well know that the significant wave height is affected by wind speed and wind direction, in the present case study, the circulation is not influenced by waves due to the three breakwaters. The hypothesis is confirmed by Lisi et al. (2009), which suggests that the circulation is influenced by tides and wind and the harbour can be analysed as a lagoon.

The particular topography, the presence of the piers and the average depth suggest that a 3D numerical code is required to reproduce the hydrodynamics of the lagoon. Furthermore, the choice is more and more efficient when parallel numerical simulations are developed.
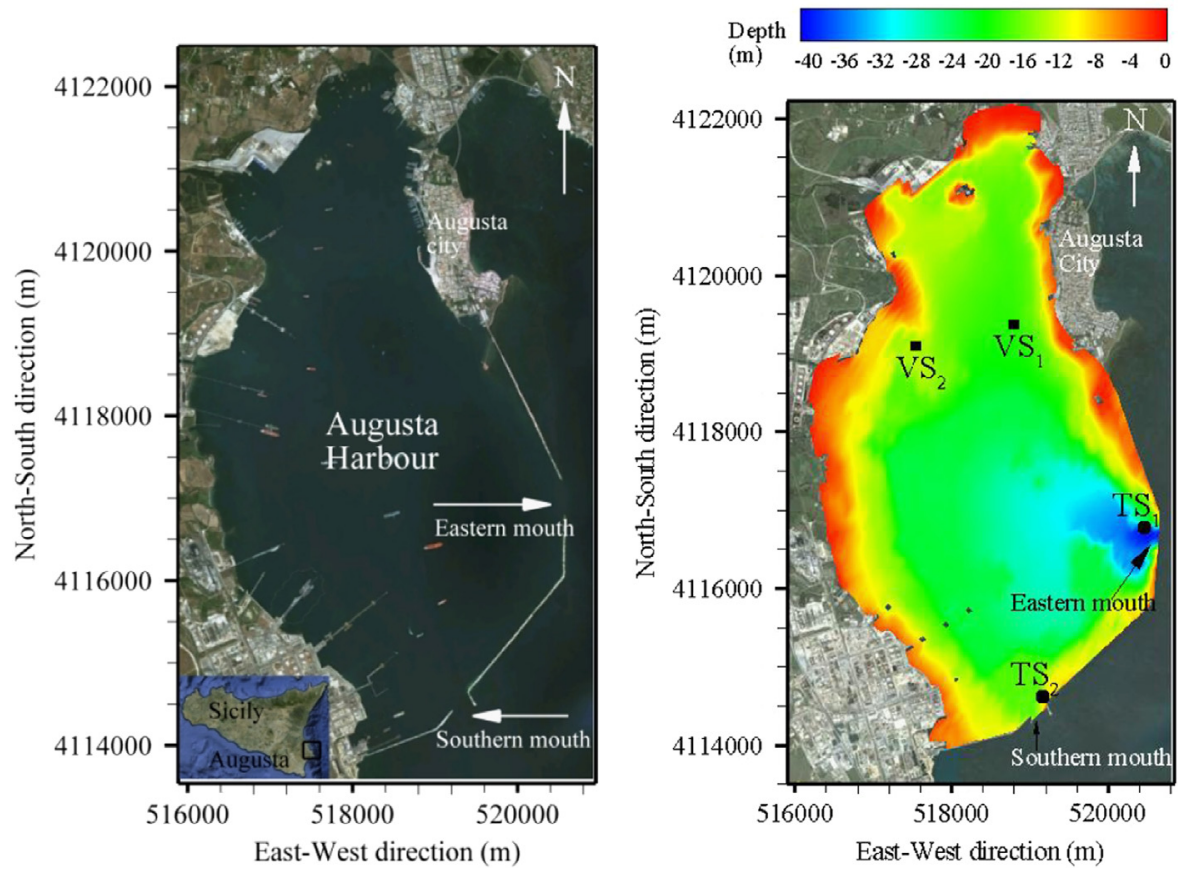

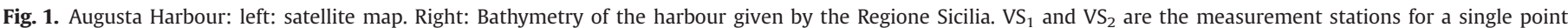
velocity. $\mathrm{TS}_{1}$ and $\mathrm{TS}_{2}$ are the measurement stations for water levels and for the vertical velocity profiles. 


\subsection{Monitoring data}

To reproduce the hydrodynamic circulation inside the harbour and validate the obtained numerical results, field campaign measurements are required. Specifically, the time variation of the water levels and wind velocities and directions were measured. The collected data were thus used as input data to force the model. Specifically, in the numerical experiments the wind field was imposed over the free surface to drive the current, while the measured water levels were applied at the two inlet mouths, shown in Fig. 1.

Velocities were measured inside the water body to compare the numerical results. The wind speed and direction, data input in the numerical model, were measured at the Augusta-Montetauro (SR) wind station, located at N372,566-E152,272, approximately $1.5 \mathrm{~km}$ from the harbour. Fig. 2a shows the wind velocity component in the period 10th-16th of October 2006. The picture shows that wind is characterised by a diurnal periodicity. The period analysed can be considered representative of the whole year, in fact, a statistical analysis of the wind speed for the 2006 year showed that the same periodicity is verified in almost all the year. Furthermore, the averaged wind speed in the whole year is $2.80 \mathrm{~m} / \mathrm{s}$, while the mean value of wind speed in the monitored period (October) is $2.65 \mathrm{~m} / \mathrm{s}$. The wind rose, plotted in Fig. 3, shows that wind is mainly directed toward the SE and SW, for both the short periods investigated here and for the whole year. Furthermore, the wind rose confirms that the period focused in the present contribution can be considered representative of the whole year. In fact, the distribution of the wind direction frequency for the two cases is quite similar.
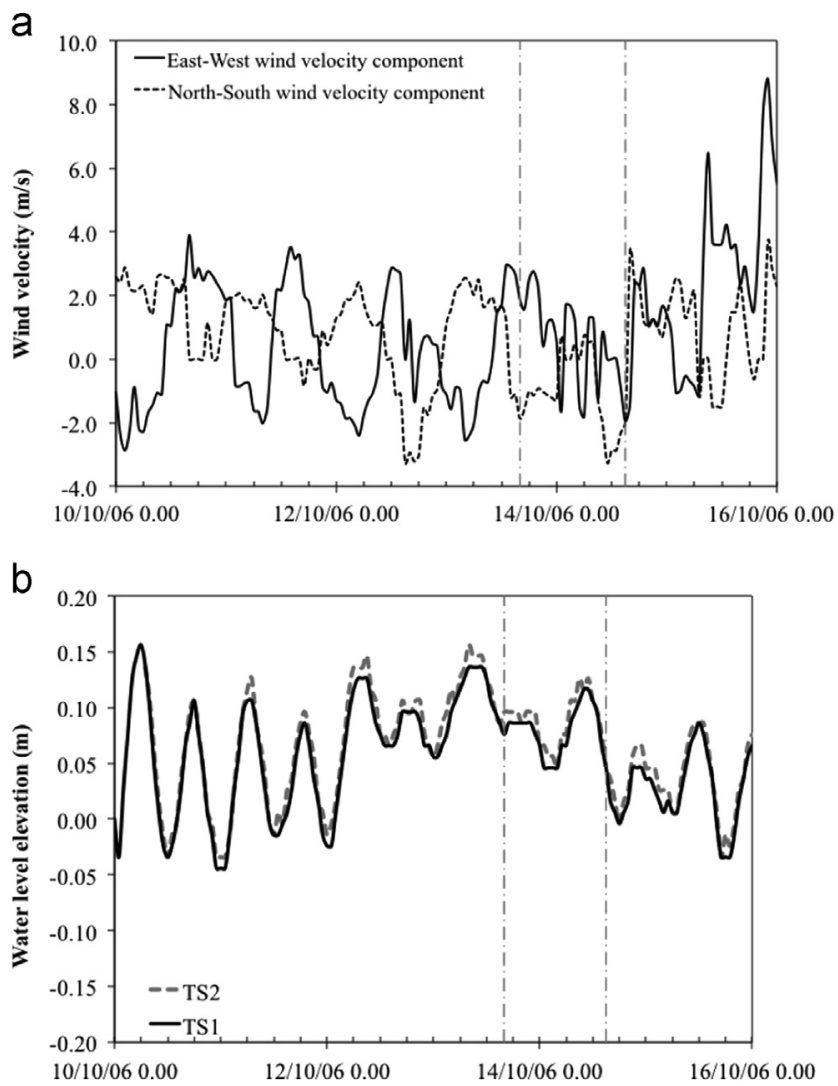

Fig. 2. (a) Wind velocity components measured at the Augusta-Montetauro (SR) wind station, located at N372,566-E152,272. (b) Free surface elevation registered at the eastern and southern mouths ( $\mathrm{TS}_{1}$ and $\mathrm{TS}_{2}$ stations). The vertical lines are representative of the time instant of the Figs. 10 and 11, respectively.

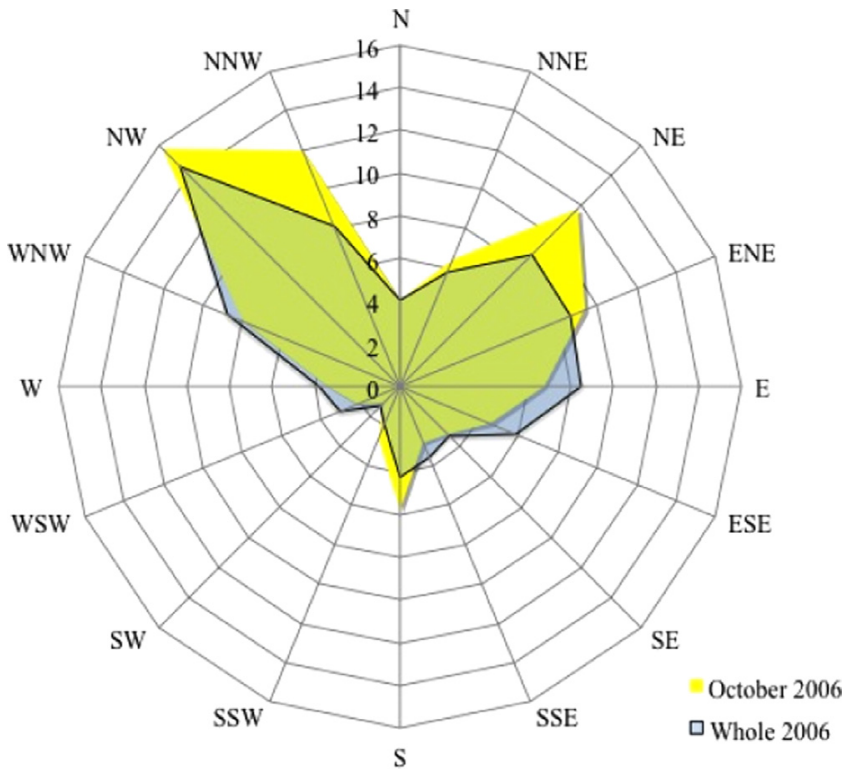

Fig. 3. Wind rose for the whole 2006 and for October 2006.

The time variations of the free surface elevation (TS, TidalStations) and the vertical velocity profile (collected through an Acoustic Doppler Cuerrent Profiler ADCP) were measured near the inlet mouths located at the eastern $\left(\mathrm{TS}_{1}\right)$ and southern $\left(\mathrm{TS}_{2}\right)$ parts of the breakwaters. Furthermore, two single point Acoustic Doppler Velocimetry (ADV) placed inside the harbour collected the current velocities. The two measurement stations are indicated in Fig. 1 ( $\mathrm{VS}_{1}$ and $\mathrm{VS}_{2}$, Velocity-Stations). The registered data were thus used to corroborate the numerical results obtained by the present simulations. The field campaign used in the present research was performed from the 10th to the 16th of October 2006. In Fig. $2 b$ the water level measured at the southern and eastern mouths ( $\mathrm{TS}_{1}$ and $\mathrm{TS}_{2}$ stations, respectively) are also plotted. The Mediterranean Sea has very low tides excursion because sufficient water cannot pass out of the straits of Gibraltar into the Atlantic Ocean fast enough. The largest tides are close to their narrow connexions with the Atlantic Ocean. The area of the Augusta harbour is far from the Atlantic Ocean, thus the effect of the spring-neap cycle (Duxbury et al., 2002) is very weak and thus in the present analysis its influence is not pointed out.

\subsection{The 3D hydrodynamic model and the numerical simulations}

To simulate the flow field inside the harbour, the Reynolds averaged continuity and momentum equations were solved. In the standard conventional summation approach, these equations can be written as

$\frac{\partial u_{i}}{\partial t}+u_{j} \frac{\partial u_{i}}{\partial x_{j}}-\nu \frac{\partial^{2} u_{i}}{\partial x_{j} \partial x_{j}}+\frac{1 \partial \tau_{i j}}{\rho \partial x_{j}}+\frac{1 \partial p}{\rho \partial x_{i}}+g d_{i j}+2 \omega \varepsilon_{i j k} n_{j} u_{k}=0 \quad i, j=1, \ldots 3$

$\frac{\partial u_{i}}{\partial x_{i}}=0 \quad i=1, \ldots 3$

where $t$ is time, $x_{i}$ is the $i$-th axis (with the east, north and vertical directions aligned with the axes $x_{1}, x_{2}$ and $x_{3}$, respectively), $u_{i}$ is the $i$-th component of the Reynolds averaged velocity, $\rho$ is the water density, $p$ is the Reynolds averaged pressure, $\nu$ is the kinematic viscosity, $g$ is the gravity acceleration, $\delta_{i j}$ is the Kronecker delta, $\tau_{i j}$ is the Reynolds stresses, $\omega$ is the earth's angular 
velocity, $\varepsilon_{i j k}$ is the permutation tensor (or Levi-Civita tensor), equal to 1 for an even permutation of the $i, j$, and $k$ indices, -1 for an odd permutation and 0 if two or more indices are equal and $n$ is the normal vector.

The pressure $p$ can be decomposed into a hydrostatic function of the free surface elevation and non-hydrostatic pressure, which is independent of the vertical coordinate

$p=\rho g\left[\left(z_{B}+h\right)-x_{3}\right]+\rho q$

where $z_{B}$ is the bed elevation from a horizontal plane of reference, $h$ is the depth of the water column and $q$ is the non-hydrostatic pressure. Introducing Eq. (3) into Eq. (1), the 3D Reynolds averaged Navier-Stokes equations can be rewritten as

$$
\begin{aligned}
& \frac{\partial u_{i}}{\partial t}+\frac{\partial u_{i} u_{j}}{\partial x_{j}}-\nu \frac{\partial^{2} u_{i}}{\partial x_{j} \partial x_{j}}+\frac{1 \partial \tau_{i j}}{\rho \partial x_{j}}+\frac{\partial q}{\partial x_{i}}+g \frac{\partial\left(z_{B}+h\right)}{\partial x_{i}}+2 \omega \varepsilon_{i j k} n_{j} u_{k}=0 \\
& \quad i, j=1, \ldots 3
\end{aligned}
$$

The term $g\left(\partial\left(z_{B}+h\right) / \partial x_{i}\right)$ is null for $i=3$ because of the independence of $z_{B}$ and $h$ from $x_{3}$. The turbulent stresses $\tau_{i j}$ are calculated using the $k-\varepsilon$ turbulence model in the 'standard' formulation (Launder and Spalding, 1974), while the free surface movements in the vertical direction are calculated according to the kinematic boundary condition (Svendsen, 2006; van Rijn Leo, 2011):

$\frac{\partial h}{\partial t}+u_{1} \frac{\partial\left(h+z_{B}\right)}{\partial x_{1}}+u_{2} \frac{\partial\left(h+z_{B}\right)}{\partial x_{2}}-u_{3}=0$

High grid anisotropy occurs due to the specifics of the case under study. The horizontal domain is, in fact, larger than the vertical. To overcome this difference, turbulence closure is achieved by using a non-isotropic eddy viscosity coefficient. Here, the non-isotropic coefficient is obtained through the sum of an isotropic coefficient $\nu_{t}$ and an horizontal eddy viscosity coefficient $\nu_{h, t}$, as customary in oceanographic applications (Roman et al., 2010; Shulman et al., 2002). The first term is given by the following equation:

$\nu_{t}=c_{\mu} \frac{\kappa^{2}}{\varepsilon}$

where $c_{\mu}$ is a closure parameter equal to 0.09. $k$ and $\varepsilon$ are the turbulent kinetic energy and its dissipation rate, respectively.

The horizontal eddy viscosity coefficient $\nu_{h, t}$, acting on the horizontal terms only, is calculated through the Smagorinsky model (it is worthwhile to point out that, although the Smagorinsky model is mainly used in the framework of the Large Eddy Simulation technique (see Galea et al., 2014), here the RANS approach is employed). The Reynolds stresses $\tau_{i j}$ of Eq. (4) are thus calculated according to

$\frac{1 \partial \tau_{i j}}{\rho \partial x_{j}}=\frac{\partial}{\partial x_{j}}\left(\nu_{t}\left(\frac{\partial u_{i}}{\partial x_{j}}+\frac{\partial u_{j}}{\partial x_{i}}\right)\right)-\left(1-\delta_{\mathrm{i} 3}\right) \cdot\left(1-\delta_{j 3}\right) \frac{\partial}{\partial x_{j}}\left(\nu_{h t}\left(\frac{\partial u_{i}}{\partial x_{j}}+\frac{\partial u_{j}}{\partial x_{i}}\right)\right)+\frac{2}{3} \delta_{i j k}$

where the product $\left(1-\delta_{i 3}\right)\left(1-\delta_{j 3}\right)$ is different from zero for $i=1$, 2 and $j=1,2$ (the horizontal terms).

The equation for $\nu_{h t}$ read

$\nu_{h t}=(c \Delta)^{2}\|S\|$

with $\Delta$, the length of the horizontal grid spacing, is calculated as the square-root of the area of the cell projection onto a horizontal plane, $c$ is the closure coefficient (constantly equal to 0.2 ) and $\|S\|$ is calculated according to $\|S\|=\left(2 S_{m n} S_{m n}\right)^{0.5}$. $S_{m n}$ represents the horizontal Reynolds averaged strain-rate tensor (details on the mathematical formulation can found in De Marchis et al. (2012)).

The system of equations briefly presented above was resolved using a 3D numerical model called PANORMUS (PArallel Numerical Open-souRce Model for Unsteady flow Simulation), available at www.panormus3D.org. The code has second-order accuracy in both time and space. The algorithm used is based on the fractional-step method, where the solution is split into two steps, a predictor-step, where the equations are solved assuming a hydrostatic pressure distribution without imposing mass conservation, and a corrector-step, where a Poisson-like equation is solved to obtain a conservative velocity field. In environmental engineering applications, it is fundamental to correctly reproduce the movement of the free surface elevation, which is calculated at each time step according to Eq. (5).

The numerical model has been parallelized using the paradigm standard of MPI (Message Passing Interface). The parallel technique for grid-based problems, known as domain decomposition, has been applied. Specifically, the numerical model is able to subdivide the computational domain into sub-domain of equal or variable size. Ideally, each processor should have the same amount of computational work. Thus, if the numerical simulations are carried out using the same CPU for each domain, the best practice is to adopt an equal partitioning. On the other hand, it is possible to balance computational cost using different cell numbers in function of the CPU's performance. One direction domain decomposition is used, taking care that the amount of data that needs to be communicated across the processor boundaries is minimal. A non-overlapping method is applied and the smoothness and continuity of the solution is ensured, at each time step, through the technique of the ghost cells at the sub-domain boundaries. Due to the limited number of grid cells, the present numerical simulations were carried out using 8 CPU's and an equal partition of the cells was used. In order to measure the performance of the parallel simulation in Fig. 4 the speed-up and the efficiency of the simulations are reported. The picture clearly shows that the parallelization procedure adopted has a good performance, with a speed-up close to the ideal one, at least for the processor here used. Furthermore, a very good level of efficiency was achieved, having a minimum of $77 \%$ when eight different CPUs are used. It is worthwhile to specify that the presented results are achieved imposing an integration time step equal to $1.5 \mathrm{~s}$ and the computational time of each iteration was equal to $0.20 \mathrm{~s}$, with eight CPUs. The results achieved suggest that the proposed numerical model can be considered a real time model. The numerical simulations were carried out in a workstation with 32 CPUs Xeon ES-2687W $3.10 \mathrm{GHz}$, having $64 \mathrm{~GB}$ of RAM. The data are collected through a Hard disk 10,000 rpm, 900 GB.

Three numerical simulations were performed to analyse the effects of wind and tide on the hydrodynamic circulation inside the Augusta Harbour. In the first simulation (hereafter referred to

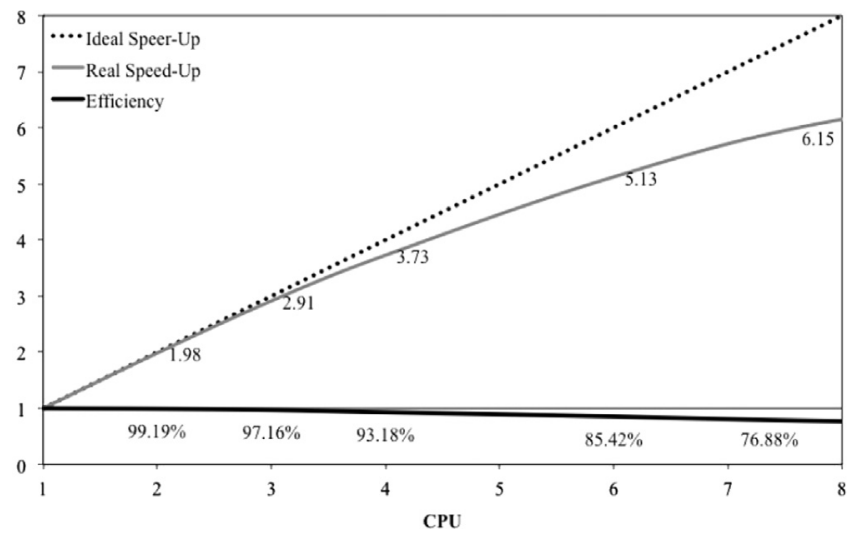

Fig. 4. Performance of the parallel numerical simulations. 
as WT, Wind-Tide), to reproduce the hydrodynamic flow field and compare the numerical results with the observed data, both water level oscillation and time variable wind speed and direction were used as input data. In the second simulation (hereafter referred to as WNT, Wind-No-Tide), the current was forced using wind speed only, thus neglecting the water level effect. In the third simulation, the wind action was neglected and the hydrodynamic was forced by the water level variations at the mouths (hereafter referred to as TNW, Tide-No-Wind). In this way, it was possible to separate the relative contribution between the effect induced by wind and the effect induced by the tide in the enclosed coastal area. In all cases, the computational domain was discretised using $64 \times 128 \times 16$ cells in the streamwise (east), spanwise (north) and vertical directions, respectively. In the vertical direction, a non-uniform grid was used with a refinement near the bottom and near the free surface. Specifically, the level of refinement was set according to the hyperbolic function given by

$d_{k}=0.5 h[\tanh (\alpha(r-1))+(\tanh (-\alpha)+1)(r-1)+1]$

where $d_{k}$ is the distance of the $k$-th node from the bottom, $r=2$ $(k-1) / n$ is a tuning parameter, with $n$ the number of grid cells in the vertical direction and $h$ is the water depth. The parameter $\alpha$ controlling the node clustering is locally tuned to obtain a vertical resolution. Specifically, $\alpha$ has been tuned to achieve cells at the top and bottom not higher than $0.1 \mathrm{~m}$ and a maximum grid spacing of about $6 \mathrm{~m}$, close to the eastern mouth. On the other hands in the horizontal directions a mean grid spacing of about $20 \mathrm{~m}$ is achieved, with a minimum value of about $15 \mathrm{~m}$ and a maximum value of about $30 \mathrm{~m}$. The smallest cells are located close to the solid boundaries, while the highest ones are located in the central harbour region.

To ensure an appropriate grid resolution, a sensitivity analysis was performed doubling the horizontal and vertical resolution, thus discretising the physical domain into $128 \times 256 \times 32$ cells. Because no discernable differences were found when the grid was refined, the coarse grid with $64 \times 128 \times 16$ cells was used; no further refinement was thus needed. This result can be attributed to the much lower resolution of the bathymetry and of the forces acting on the harbour.

To simulate the flow in the lagoon, the logarithmic wall-law is used at the bottom, at the open boundaries (eastern and southern mouths) the measured water level is imposed to force the current and the free slip conditions are imposed at the land boundaries. At the free surface the shear stress induced by the wind is imposed and calculated according to equation $\tau_{s}=\rho_{\text {air }} u^{* 2}$, where $\rho_{\text {air }}$ is the air density and $u^{*}$ is the air friction velocity at the free surface, which is usually related to the wind speed velocity $W_{10}(\mathrm{~m} / \mathrm{s})$ at a standard height of $10 \mathrm{~m}$ using the drag coefficient $C_{10}=\left(u^{*}\right)^{2} /$ $\left(W_{10}\right)^{2}$. The wind drag coefficient is calculated by the widely employed Wu's formula (Wu, 1982): $C_{10}=\left(0.8+0.65 \times W_{10}\right) 10^{-3}$.

Wind speed at the standard height of $10 \mathrm{~m}$, in a neutral atmospheric surface layer, can be calculated as logarithmic function of the horizontal wind speed at height $z$ above the surface according to the equation (see Homoródi et al., 2012)

$W_{z}=\frac{u^{*}}{k} \ln \frac{z}{z_{0}}$

where $k=0.4$ is the von Kármán's constant and $z_{0}$ is the surface roughness length $(\mathrm{m})$ related to the wind friction velocity $u^{*}$ and the acceleration due to gravity through the formula

$z_{0}=0.0185 \frac{u^{* 2}}{g}$

The wind velocity $W_{10}$ is decomposed in east $\left(W_{10 \text {,east }}\right)$ and north $\left(W_{10, \text { north }}\right)$ directions and thus two components of the wind shear stresses are calculated according to $\tau_{s, \text { east }}=\rho_{\text {air }} W_{10, \text { east }}\left|W_{10 \text {,east }}\right| C_{10}$ and $\tau_{s, \text { north }}=\rho_{\text {air }} W_{10, \text { north }}\left|W_{10, \text { north }}\right| C_{10}$

Due to the geometrical complexity of the domain and the presence of artificial barriers and several piers, a curvilinear boundary-fitted computational grid was used where the cells corresponding to land areas were excluded from the computation. Homogeneous sediments cover the bottom, thus a unique value of Nikuradse roughness coefficient $\varepsilon(\mathrm{m})$ is used in the logarithmic velocity profile of the wall law. Preliminary, with the aim to investigate the roughness sensitivity, three tests were performed imposing different values of roughness equal to $0.02 \mathrm{~m}, 0.05 \mathrm{~m}$ and $0.1 \mathrm{~m}$. In order to quantify the differences between the three simulations the root mean square error (RMSE) was calculated to estimate the absolute error, according to

$\mathrm{RMSE}=\sqrt{\frac{1}{n} \Sigma(\mathrm{O} i-\mathrm{Pi})^{2}}$

where $n$ is the number of observations.

The RMSE $(\mathrm{m} / \mathrm{s})$ of the velocity time series achieved with roughness coefficients 0.02 and $0.05 \mathrm{~m}$ is equal to 0.027 . The RMSE given considering $\varepsilon=0.05$ and $\varepsilon=0.1$ is equal to 0.032 . The low RMSE values suggest that the flow field is not sensitive to the bed roughness. All simulations presented here were thus carried out with a Nikuradse roughness coefficient of $5 \mathrm{~cm}$. In order to avoid numerical oscillation at the beginning of the simulation, a spin-up period of two hours was considered, imposing a constant wind equal to the value registered at $10 / 10 /$ 2006 0:00.

The numerical model was extensively validated against physical problems (Milici et al., 2014), laboratory and field experiments in several different conditions. Details can be found in De Marchis and Napoli (2008), Napoli et al. (2008), and De Marchis and Napoli (2012).

\section{Results and discussion}

\subsection{Model validation}

To validate the applied simulation code, the numerical results obtained using both wind and water level variation forces were compared with the data collected in a field campaign. Fig. 5 shows the velocity time history in the $\mathrm{VS}_{1}$ measurement station, at depth of approximately $10 \mathrm{~m}$. The velocities were acquired through an Acoustic Doppler Velocimeter (ADV). The data were acquired with a sampling rate of $25 \mathrm{~Hz}$. The accuracy of the used ADV was within $0.5 \%$ of the measured velocity $\pm 2.5 \mathrm{~mm} / \mathrm{s}$. Finally, the data were filtered thus obtaining a value every $10 \mathrm{~min}$. The numerical and measured velocity patterns here shown were filtered by means of a low-pass filter, thus removing the seiche oscillations and focusing the attention on the large scales variation of the velocity field. The ability of the numerical model to reproduce the seiche motion was object of a previous research (see De Marchis et al., 2012) and is not addressed in the present analysis.

The comparison between measured and modelled velocities (Fig. 5) shows that the general feature of the measured velocities is well reproduced through the numerical simulation, especially in the north direction. In the east direction, a lower agreement is found. On the other hand, in the $\mathrm{VS}_{2}$ station (Fig. 6) the opposite holds; a good agreement was observed in the east direction, while lower agreement was found in the north direction. The opposite behaviour can be explained by considering that in the $\mathrm{VS}_{1}$ point the flow is mainly driven in the north direction, while the highest velocities were registered in the east direction in the $\mathrm{VS}_{2}$ station. However, all comparisons show that the variation of the velocity in time is well captured. In order to provide a quantitative measure of 
a

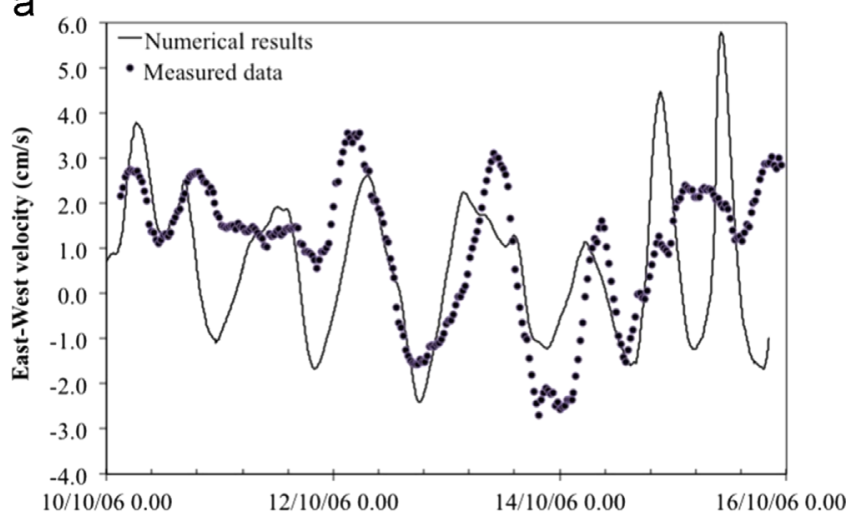

b

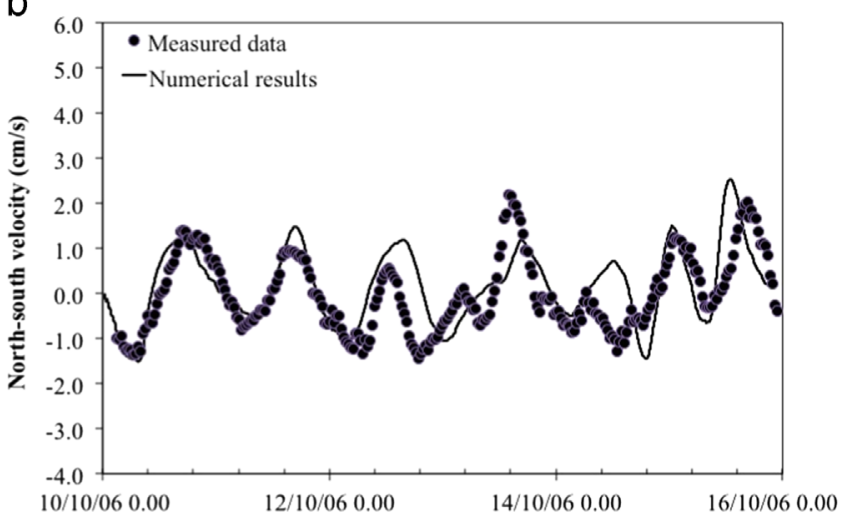

Fig. 5. Comparison between measured and modelled velocity components at the $\mathrm{VS}_{1}$ station, located at a depth of approximately $10 \mathrm{~m}$. (a) East velocity component and (b): North velocity component. The measured and modelled results were filtered by applying the low-pass Butterworth filter, thus removing the seiche oscillations.

the agreement between measured and modelled velocities in the horizontal directions, two coefficients, able to measure the goodness of the obtained data, are calculated. Specifically, the NashSutcliffe model efficiency coefficient $E$ (Nash and Sutcliffe, 1970) was calculated, according to the following equation:

$E=1-\frac{\Sigma|O i-P i|^{2}}{\Sigma|O i-O|^{2}}$

where $\mathrm{Oi}$ and $\mathrm{Pi}$ are the observed and predicted values of the variable at each time step $i$, and $O$ is the mean of the observed values of the variable.

Due to the high variability of the velocities in a real environmental flow field and considering a typical diurnal periodicity verified in the measured data, daily values of the two parameters were calculated. The achieved values are reported in Table 1.

The quantitative analysis, reported in Table 1, demonstrates the qualitative agreement already observed in Figs. 5 and 6. Specifically, the values obtained for the Nash Sutcliffe model efficiency coefficient are quite high for the north component of the velocity compared in the $\mathrm{VS}_{1}$ monitoring point. A perfect agreement is achieved for $E=1$, here a value of about 0.71 is obtained. On the other hands, a value of efficiency of 0.46 is registered for the east component of the velocity in the same location, where the velocity time series showed lower agreement. Similar results hold for comparison in the $\mathrm{VS}_{2}$ point, where a value of $E=0.70$ is obtained for the east component, while a lower level of efficiency $(E=0.3)$ is observed in the other direction. Similar consideration can be reported analysing the RMSE, characterised by an optimal value
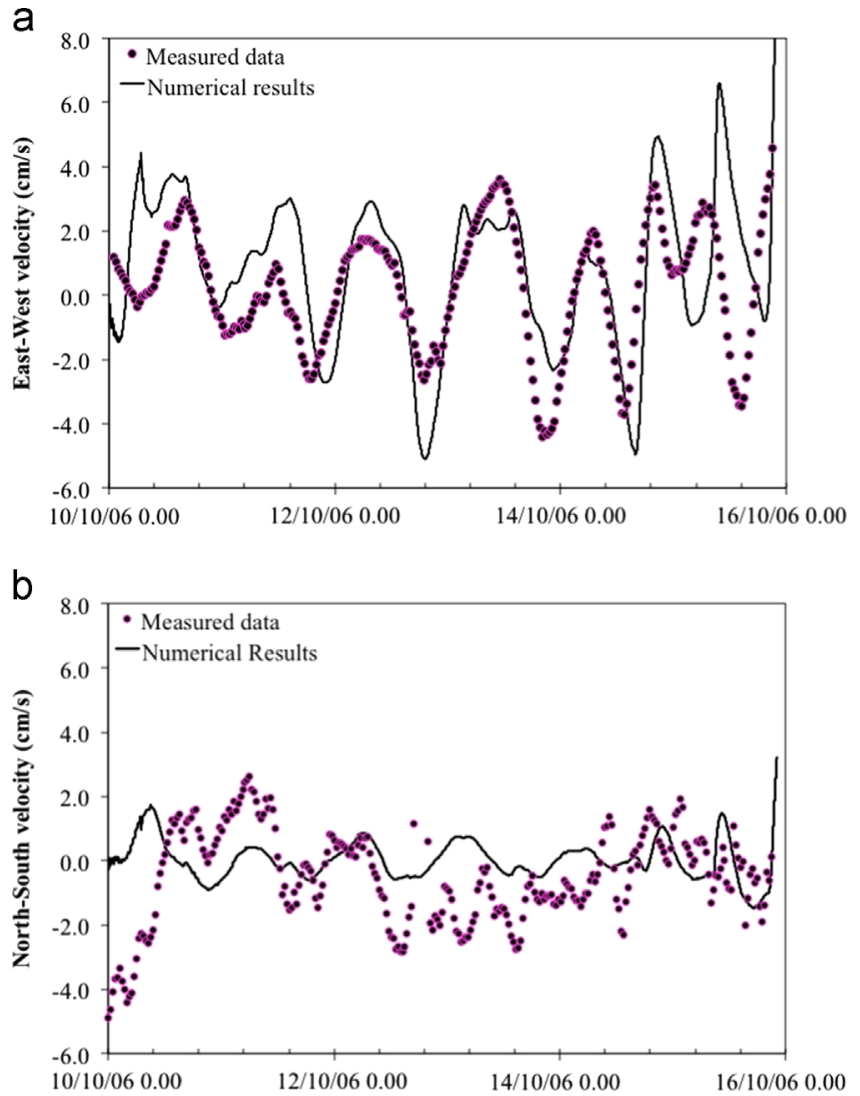

Fig. 6. Comparison between measured and modelled velocity components in the VS2 station, located at a depth of approximately $10 \mathrm{~m}$. (a) East velocity component and (b) north velocity component. The measured and modelled data were filtered by applying the low-pass Butterworth filter, thus removing the seiche oscillations.

Table 1

Analysis of the goodness of the numerical simulations. E: Nash-Sutcliffe mode efficiency coefficient; RMSE: Root Mean Square Error.

\begin{tabular}{lllllll}
\hline & VS1 East & VS1 North & VS2 East & VS2 North & TS1 & TS2 \\
\hline E & 0.46 & 0.71 & 0.70 & 0.3 & 0.76 & 0.73 \\
$\operatorname{RMSE}(\mathbf{m} / \mathbf{s})$ & 0.85 & 0.37 & 0.39 & 1.03 & 0.08 & 0.09 \\
\hline
\end{tabular}

equal to zero. In all cases the achieved values are higher than 0.37 but lower of 1.03, confirming that, even some differences between measured and simulated are verified, globally the numerical model is able to reproduce the hydrodynamic behaviour.

The differences between the modelled and measured velocities could be attributed to the input wind over the free surface being measured in a location far from the harbour (approximately $1.5 \mathrm{~km}$ ). Moreover, the wind was considered variable in time but constant in space, thus neglecting the wind speed changes occurring close to the coastlines due to the different land and water roughness.

In Fig. 7 the magnitude of the vertical velocity profiles obtained with the numerical simulations and through field measurements are compared. The two profiles were collected by means of the two ADCP located at the stations $\mathrm{TS}_{1}$ and $\mathrm{TS}_{2}$ (see Fig. 1), having an acoustic frequency of $1200 \mathrm{kHz}$. The sampling rate was imposed equal to $1 \mathrm{~Hz}$. The velocity profiles, both numerical and experimental, shown in Fig. 7 were averaged in time. 
a

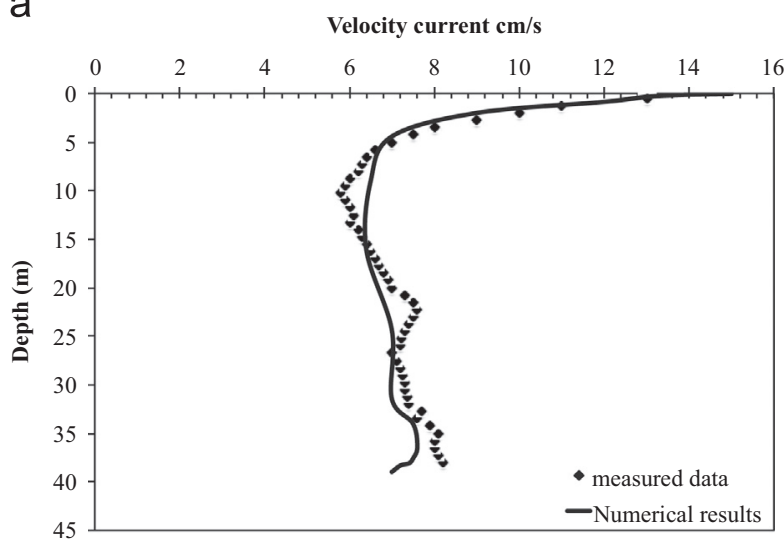

b

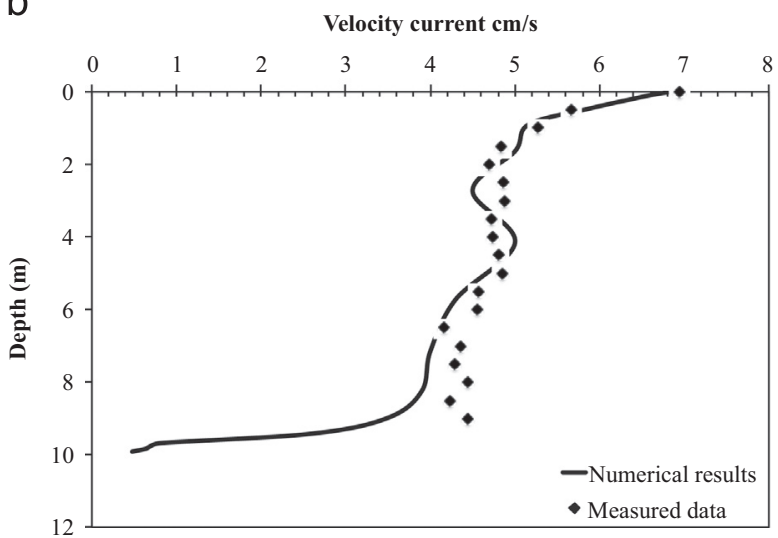

Fig. 7. Comparison between measured and modelled velocity module profile in the $\mathrm{TS}_{1}$ (a) and $\mathrm{TS}_{2}$ (b) measurement stations. The measured data were acquired through Acustic Doppler Current Profiler (ADCP). The velocities are tidally averaged.

Specifically, the velocity were averaged during the tide period between October 10th at $6 \mathrm{pm}$ and October 11th at $7 \mathrm{am}$. A good agreement between measured and modelled results is also achieved, despite slight differences are observed in the deeper layers of the harbour. In Table 1 the values of Nash-Sutcliffe efficiency and RMSE are reported. The efficiency values higher than 0.7 and the RMSE lower than 0.1 can be considered, in environmental flow fields, indicators of a good quality of the numerical model, thus demonstrating the ability of the model to reproduce the velocities in the vertical direction too.

The comparison between numerical and field data shows that in the TS1 monitoring station, close to the bottom, a rapid reduction of the velocities is observed in the numerical profile. This should be attributed to the low level of water exchange between the southern mouth, as will be shown in the next paragraph. On the other hand, velocities close to the free surface are considerably higher. This is due to the wind shear stress acting over the free surface.

The variability of the velocity profiles along the vertical direction suggests the need of 3D numerical models with respect to 2D or hydrostatic 3D models.

\subsection{Selective analysis of the wind and tide}

To preserve the coastal area and control the water quality in semi-enclosed harbours, the analysis of the different forces acting on the water body is certainly of interest. In the following section,
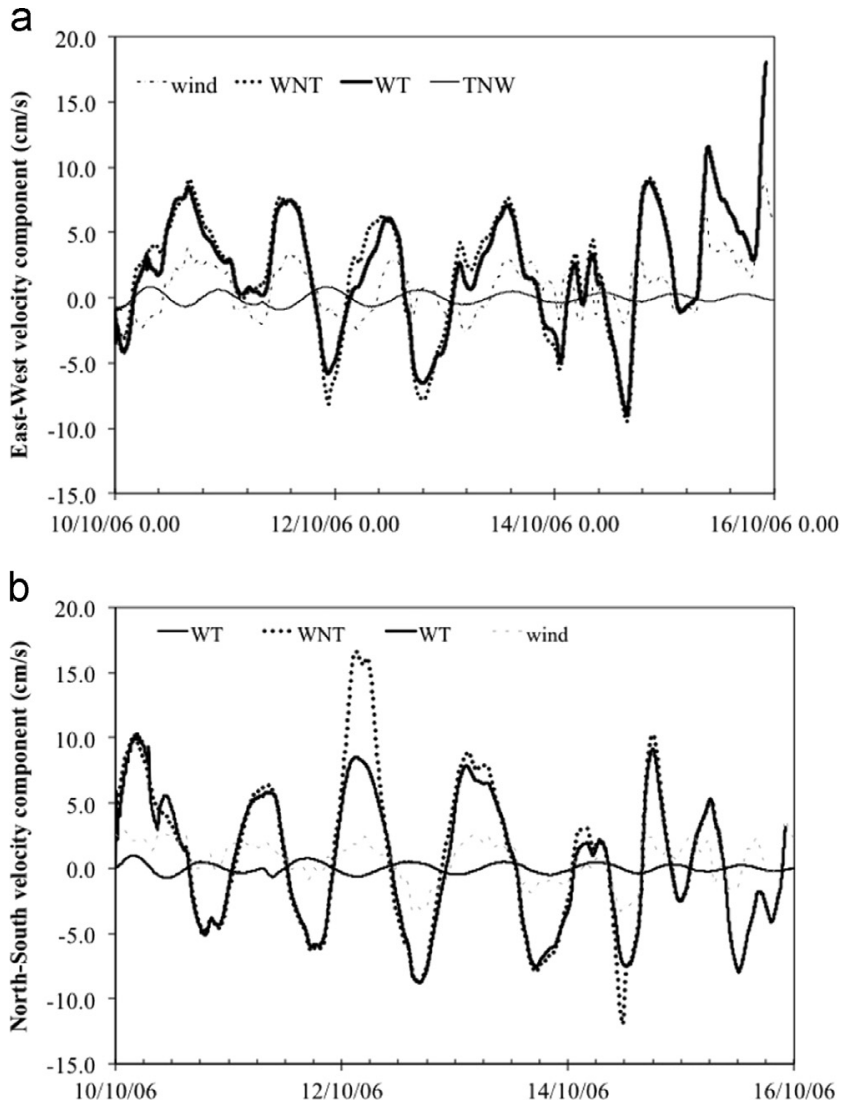

Fig. 8. Comparison between the velocity components (a: East and b: North) obtained with the three numerical simulations (WT, WNT, TNW) in correspondence with the $\mathrm{VS}_{1}$ point. The velocities are registered at $10 \mathrm{~cm}$ below the free surface. The wind velocity component is expressed in $\mathrm{m} / \mathrm{s}$.

the three numerical simulations WT, WNT and TNW, presented in a previous section, are compared to investigate the relative contribution of wind and tide in the circulation pattern. A similar analysis was recently carried out by De Marchis et al. (2012), in the Stagnone lagoon. In that research, anyway, the case of study was particularly different. The Stagnone is in fact characterised by very shallow water with a mean depth of about $1 \mathrm{~m}$. Furthermore, the bottom is partially covered by two main species of seagrass, sometimes emerging during low tide. On the other hand, the Augusta harbour, characterised by higher depth, with values of about $40 \mathrm{~m}$, and by absence of bottom vegetation, is more representative of the typical harbours of the Mediterranean sea. Thus, the results here achieved can be extended to other lagoons.

Fig. 8 shows a comparison of the velocity components for the three test cases at a mean value of about $10 \mathrm{~cm}$ below the free surface in the $\mathrm{VS}_{1}$ measurement station. The velocity time sequences obtained for the two test cases WT and WNT have a very similar pattern. Furthermore, the time series present a pattern very similar to the registered wind component. The velocities obtained for the test case TNW, conversely, is characterised by lower values (one order magnitude) than the other cases and are not related, as was expected, with the wind velocity time series.

To check the relative contribution of the two forces in the deeper layers, Fig. 9 compares the velocities at $13 \mathrm{~m}$ below the free surface, in the $\mathrm{VS}_{1}$ measurement point, corresponding to a medium depth. The picture clearly shows that the velocities are quite lower than those observed near the free surface. Also in this 
a
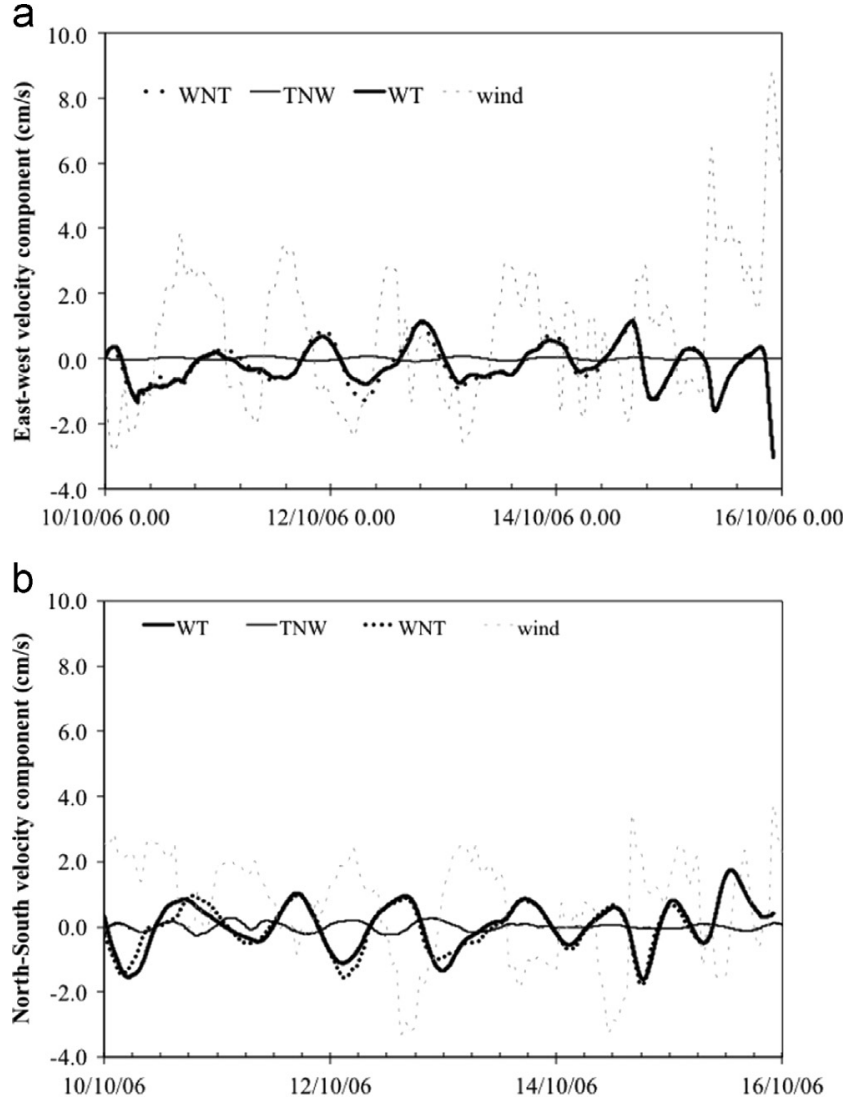

Fig. 9. Comparison between the velocity components (a: East and b: North) obtained with the three numerical simulations (WT, WNT, TNW) in correspondence with the $\mathrm{VS}_{1}$ point. The velocities are registered at a $13 \mathrm{~m}$ depth.

case, the velocities achieved in the test case TNW are clearly lower than those obtained when the wind is considered. The comparison between Figs. 8 and 9 shows that an opposite direction is obtained for the current near the free surface and in a middle layer, i.e., when the flow is directed eastward at a depth of $10 \mathrm{~cm}$, the current is directed in the opposite direction in the medium layer, with a typical profile of vertical circulation. This kind of recirculation usually happens in flow field mainly driven by the wind acting over the free surface and holds for almost all the time, especially in enclosed basin like harbours or lakes. The results thus seem to suggest that the wind is responsible for the hydrodynamic mixing in the water body. This variability of the velocity field in the vertical velocity profile, already shown in Fig. 7, demonstrates the importance of using 3D numerical solvers.

The effects of the forces acting in the Augusta Harbour, discussed above, are clearly evident in Figs. 10 and 11, where the contour plots of the velocity magnitude are reported, at 4 p.m. 13 th October and at 3 p.m. 14th October, respectively. The comparison between the three numerical simulations WNT, WT and TNW is plotted. To improve the clarity, the two instants reproduced in Figs. 10 and 11 are also identified in Fig. 2 with two dotdashed vertical lines. The two instants are representative of two frequent conditions. Fig. 10 shows an event where the wind is mainly directed toward the eastern mouth, while Fig. 11 shows an event with wind blowing toward the southern mouth, that are representative of two different tidal condition, despite the differences of $23 \mathrm{~h}$. The two instants represent the more frequent condition of wind direction, as observed in Fig. 3, where the wind rose for the whole 2006 and for October 2006 is plotted. In the present analysis we put in light the results of realistic simulation because it was demonstrated (Grifoll et al., 2014) that in enclosed basin the hydrodynamic behaviour could not be deduced from the combination of simple idealised scenarios.

In Fig. 10 is reported the contour of the velocity magnitude both at a depth of $20 \mathrm{~cm}$ (Figs. 10a-c) and of $4.20 \mathrm{~m}$ (Figs. 10d-f). Streamlines are superimposed to the velocity contours, thus revealing the current direction. Fig. 10 shows that near the free surface wind plays a fundamental role in driving the current.

The velocity magnitude is, in fact, one order of magnitude higher when the wind is considered. This result disagrees with those observed by De Marchis et al. (2012), where it was found that tide mainly drives the current in the north direction. Furthermore, in that research the authors showed that the velocities obtained considering the wind force (WT) or neglecting it (TNW) are almost comparable in module. The difference can be attributed also to the fact that in the shallow lagoon the water level differences at the mouths are much larger than in Augusta harbour, furthermore at the Stagnone the mouths are located at the endpoints of the lagoon, in contrast to nearby positions at Augusta Harbour.

Despite in the present case the wind plays a key role, when drafting an appropriate environmental policy for marine conservation of the Augusta Harbour, tide cannot be neglected. At a medium depth, in fact, the current is also driven by the oscillations, at least close to the mouths. In Fig. 10e, in fact, the streamlines are directed toward the two mouths and the highest velocity is registered close to the open boundaries. On the other hand, when the wind is considered (Fig. 10d and f), the streamlines do not reveal a unique direction. Despite of this, the highest velocity magnitude is observed at the mouths, especially in Fig. 10f, where the tide is considered.

Similar considerations can be carried out through the analysis of the contour plots of Fig. 11 where the contours of the velocity magnitude, both at a depth of $20 \mathrm{~cm}$ (Fig. 11a-c) and of $4.20 \mathrm{~m}$ (Figs. 11d-f), are reported. Again, streamlines are superimposed to the velocity contours, thus revealing the current direction. Fig. 11b and e confirms the role of the tide in the water exchange. The tide is therefore the primary force leading to mass transfer between the harbour and the open sea. The discharge of water toward the open sea carries with it the potential risk of dispersion of water and/or polluted sediment. This aspect is better analysed in Fig. 12 where the water discharge through the eastern and southern mouths is plotted against the time, for the period considered. The discharge obtained for the cases WT and TNW, Fig. 12a and b respectively, is very similar in magnitude. On the other hand, when the tide contribution is neglected (Fig. 12c), the discharge through the two mouths is almost negligible. Usually, wind should also create a water level difference on the seaside of the two mouths that may contribute to mass exchange between the sea and the harbour, especially when constant wind is considered. Nevertheless, Fig. 12c shows a very weak influence of the wind in the mass exchange between the two mouths, thus in the present contribution the analysis of the water level difference at the mouths induced by the wind was neglected. Furthermore, Fig. 12 clearly shows that the volume exchange between the harbour and the open sea through the eastern mouth is larger than that of the southern inlet. The different depths of the mouths, eastern mouth is much deeper than the southern inlet, should affect this result. Similar results were observed for all the simulated periods, partially confirming the findings of Lisi et al. (2009), even if our results strengthen the reduced effect of the wind to mass exchange through the mouth. This should be attributed to the different wind boundary conditions. Specifically, Lisi et al. (2009) carried out numerical simulations considering a constant wind speed and direction. Conversely, the present 
a

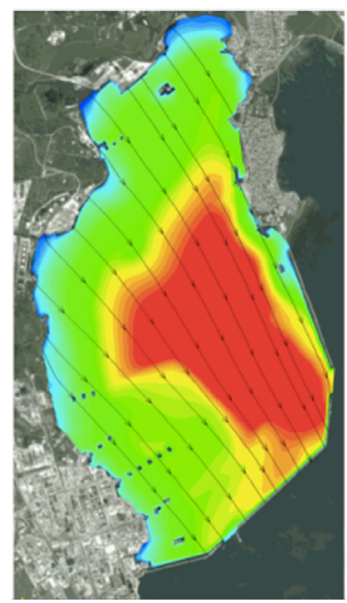

d

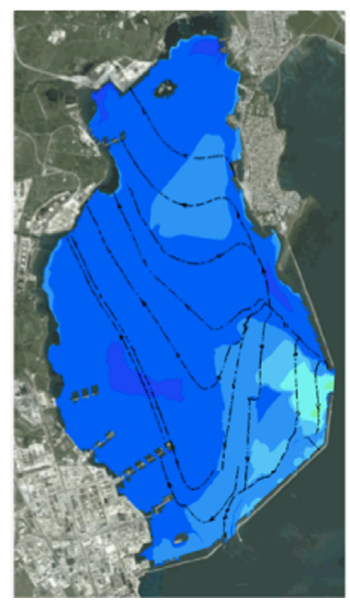

b
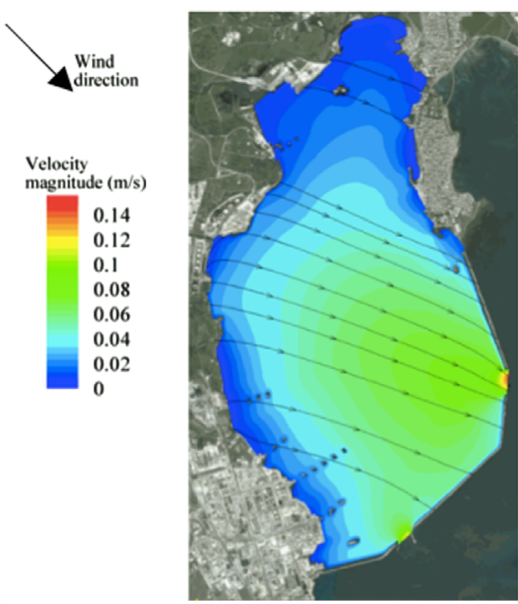

e

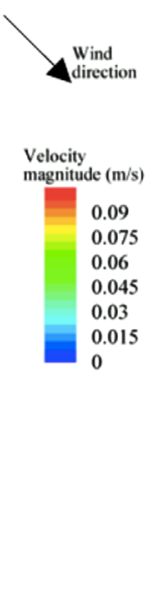

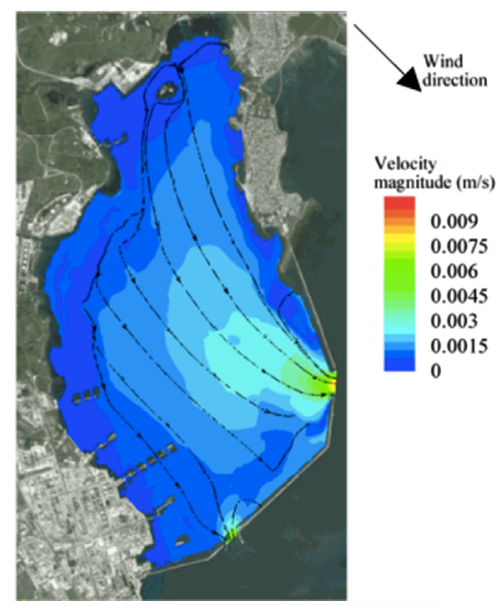

C

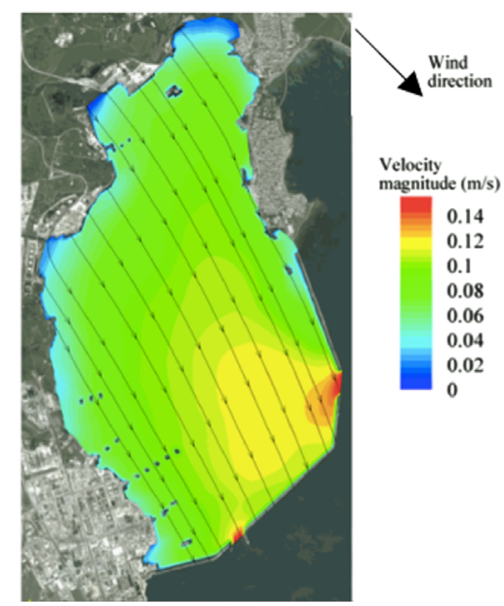

f

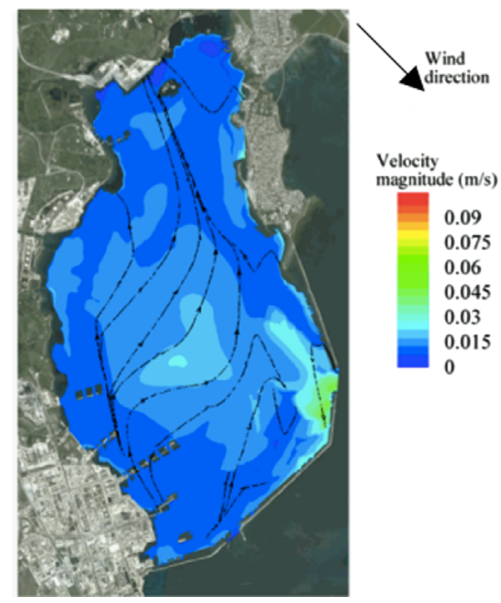

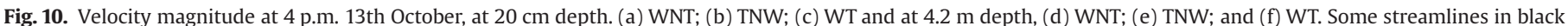

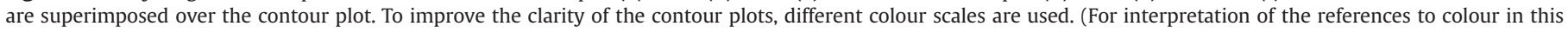
figure legend, the reader is referred to the web version of this article.)

analysis was performed imposing a time dependent wind speed and direction.

\section{Conclusion}

In this contribution, the hydrodynamic flow field in the Augusta harbour located on the east coast of Sicily (Italy) has been investigated for the first time using 3D numerical modelling. To validate the numerical model, the results were compared with measured data. The comparison showed the ability of the code to reproduce the hydrodynamics inside the harbour. Both the pattern and the range of the current velocity were well captured. The validity of the numerical results was corroborated by a quantitative analysis carried out using Nash and Sutcliffe efficiency and root mean square error performance parameters. The numerical model was thus used to separate the effects of wind and tide on the flow field. The comparison of three different numerical simulations, forcing the current with wind and tides (case WT), wind only (case WNT) and only tides (case TNW), was performed. The analysis shows that the wind plays a key role in the harbour circulation, while the velocities achieved considering only the tide are one order of magnitude lower than the registered ones. The comparison between the numerical experiments carried out considering both wind and tide and considering only the wind as driving forces, pointed out that the velocity magnitude is almost comparable. On the other hand, the analysis about the water exchange between the harbour and the open sea showed that discharges through the eastern and southern mouths are mainly due to the tide variation in time.

In this analysis, although the numerical results showed the ability to reproduce the observed data, in some periods, some difference between the measured and simulated velocities were found. This could be attributed to some simplifying assumptions, as a constant spatial distribution of the wind over the free surface or the hypothesis of no-stratification. In further analysis, a more accurate spatial distribution of wind, taking into account the internal boundary layer (IBL) development, due to the different levels of roughness of the land and water surfaces, is under investigation as well as the effect of the stratification.

The study here proposed, by means of realistic numerical simulations, suggests that harbour circulation cannot be deduced from the combination of simple idealised scenarios and a combination of the different forces is needed to reproduce reasonable flow field in environmental applications. This contribution analyses a specific case of the Augusta harbour, one of the most important economical Italian port, nevertheless the obtained results could be useful for several other enclosed basins 
a

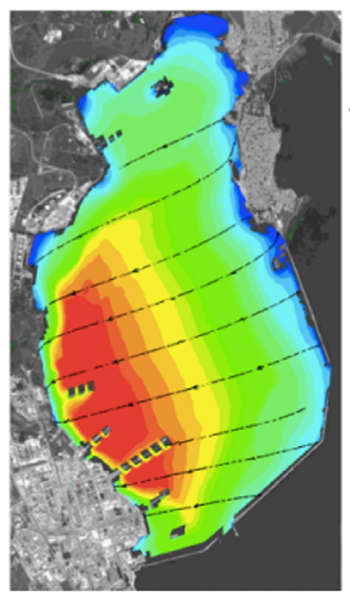

d

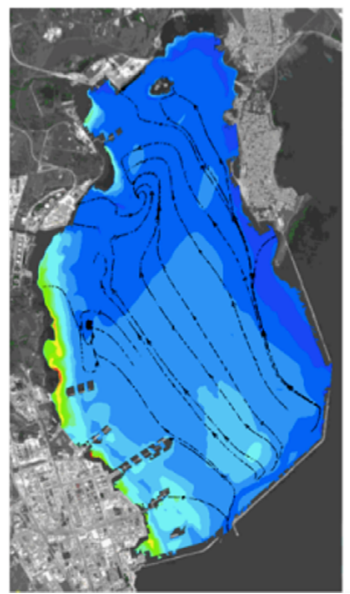

b
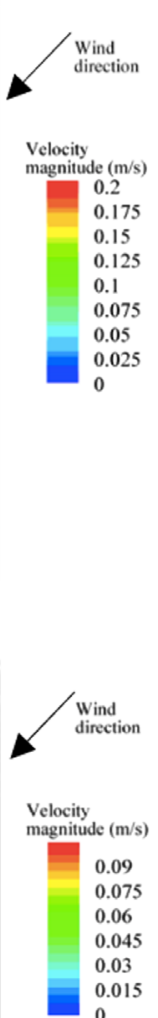

e
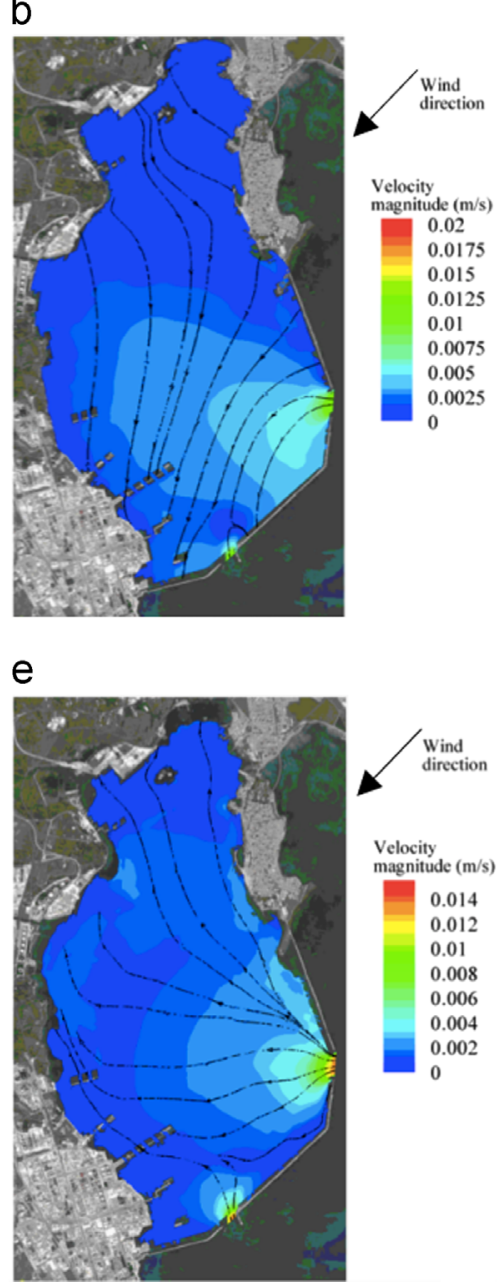

C

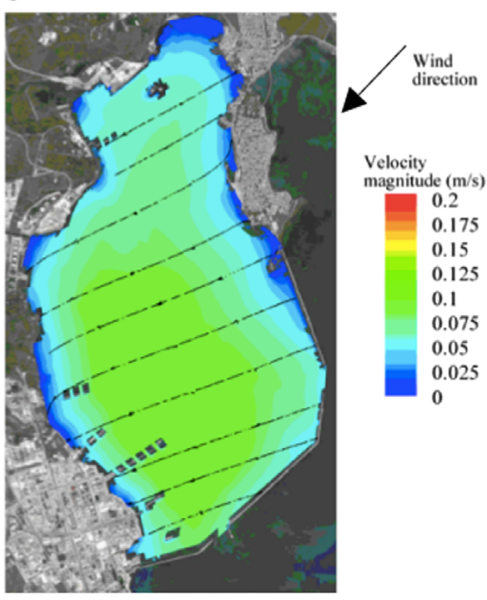

f

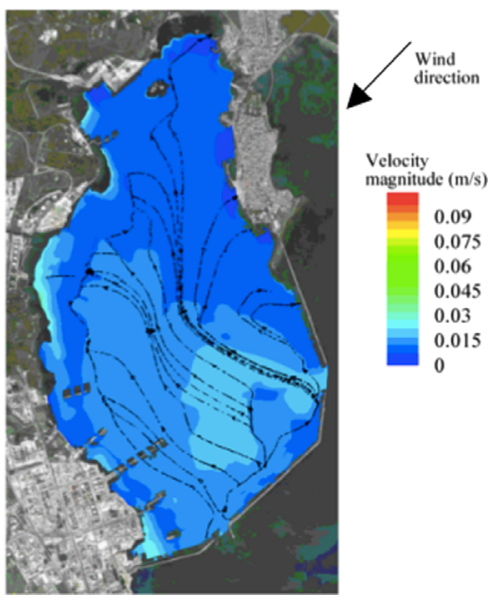

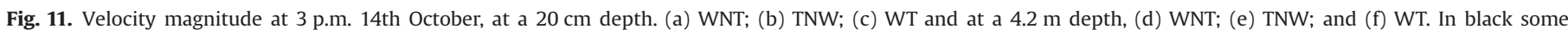

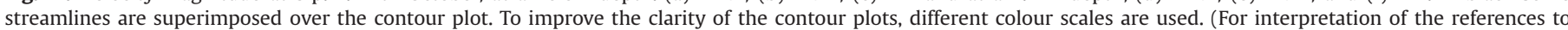
colour in this figure legend, the reader is referred to the web version of this article.)
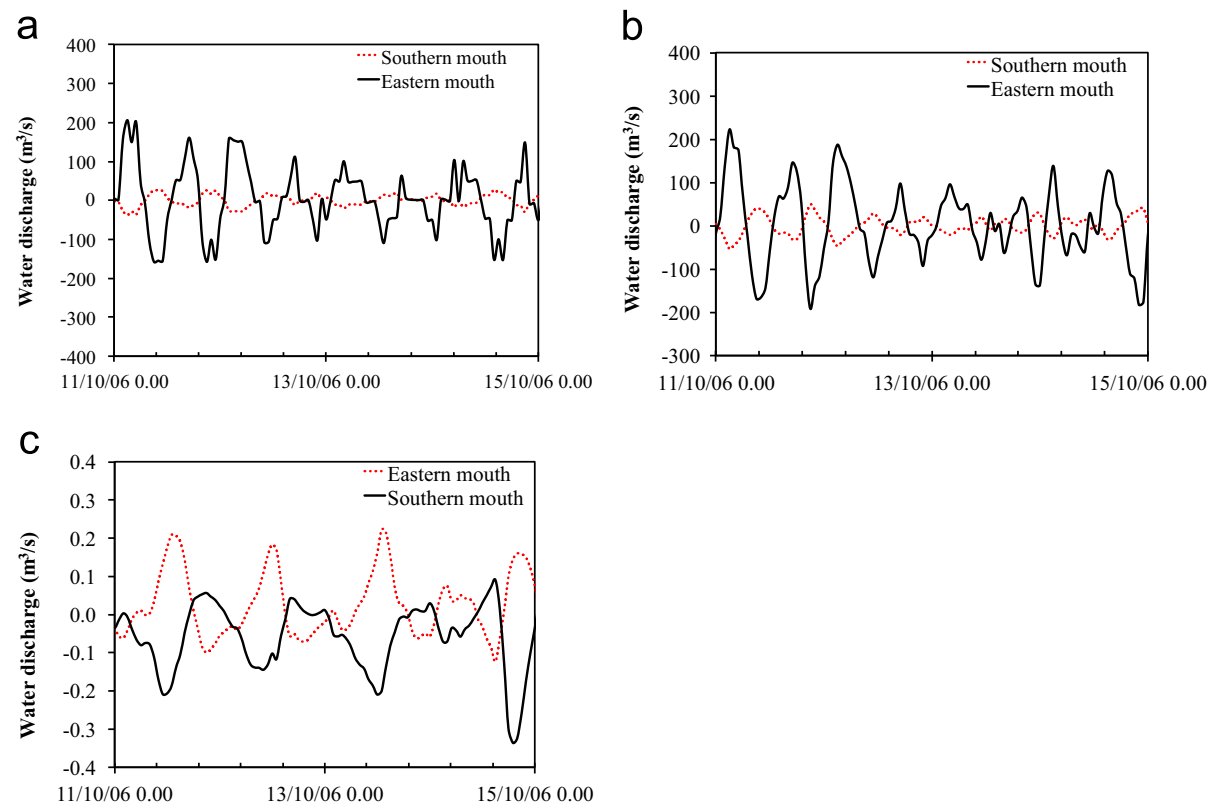

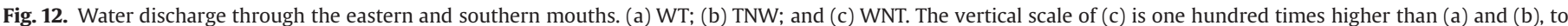
improve the clarity. 
where the hydrodynamic is mainly driven by tides and variable winds.

\section{Acknowledgements}

The authors would like to acknowledge the Italian Research Project PON 01_1844 SIBSAC for providing funding for the discussed research, the Authority "Dipartimento dell'acqua e dei rifiuti - Regione Siciliana” ex O.C. D.P.C.

\section{References}

Babu, M.T., Vethamony, P., Desa, E., 2005. Modelling tide-driven currents and residual eddies in the Gulf of Kachchh and their seasonal variability: A marine environmental planning perspective. Ecol. Model. 184, 299-312.

Balas, L., Ozhan, E., 2002. Three-dimensional modelling of stratified coastal waters estuarine. Coast. Shelf Sci. 54, 75-87.

Caviglia, F.J., Dragani, W.C., 1996. An improved 2-d finite-difference circulation model for tide- and wind-induced flows. Comput. Geosci. 22 (10), 1083-1096.

De Marchis, M., Napoli, E., 2008. The effect of geometrical parameters on the discharge capacity of meandering compound channels. Adv. Water Resour. 31, $1662-1673$.

De Marchis, M., Ciraolo, G., Nasello, G., Napoli, E., 2012. Wind and tide-induced currents in the Stagnone Lagoon (Sicily). Environ. Fluid Mech. 12, 81-100.

De Marchis, M., Napoli, E., 2012. Effects of irregular two-dimensional and threedimensional surface roughness in turbulent channel flows. Int. J. Heat Fluid Flow 36, 7-17.

De Marchis, M., Freni, G., Napoli, E., 2013. Modelling of E. coli distribution in coastal areas subjected to combined sewer overflows. Water Sci. Technol. 68 (5), $1123-1136$.

Di Bella, G., Freni, G., Giustra, M.G., Luciano, A., Mancini, G., Notaro, V., Pulvirenti, R. Ticali, A., Venusino, G., 2013. SIBSAC - an integrated system for sediments remediation and high salinity marine wastewaters treatment. In: Proceedings of the Atti del Convegno LET 2013 - Advanced Programme and Invitation to Register 10th IWA Leading Edge Conference on Water and Wastewater Technologies, Bordeaux, France, 2-6 June 2013.

Duxbury, A.B., Duxbury, A.C., Sverdrup, K.A., 2002. Fundamentals of Oceanography, fourth ed. McGraw Hill, Boston p. 344.

Ferrarin, C., Umgiesser, G., 2005. Hydrodynamic modeling of a coastal lagoon: the Cabras lagoon in Sardinia, Italy. Ecol. Model. 188, 340-357.

Galea, A., Grifoll, M., Roman, F., Mestres, M., Armenio, V., Sanchez-Arcilla, A. Mangio, L.M., 2014. Numerical simulation of water mixing and renewals in the Barcelona harbour area: the winter season. Environ. Fluid Mech. , http://dx.doi. org/10.1007/s10652-014-9351-6.

Grifoll, M., Fontán, A., Ferrer, L., Mader, J., González, M., Espino, M., 2009. 3D hydrodynamic characterisation of a meso-tidal harbour: the case of Bilbao (northern Spain). Coast. Eng. 56, 907-918.

Grifoll, M., Jordà, G., Espino, M., 2014. Surface water renewal and mixing mechanisms in a semi-enclosed microtidal domain. The Barcelona harbour case. J. Sea Res. 90, 54-63.
Homoródi, K., Józsa, J., Krámer, T., 2012. On the 2D modelling aspects of windinduced waves in shallow, fetch-limited lakes. Period. Polytech.: Civil Eng. 56 (2), 127-140.

Krámer, T., Józsa, J., 2004. An adaptively refined, finite-volume model of windinduced currents in lake neusiedl. Period. Polytech. Ser. Civ. Eng. 49 (2), $111-136$.

Launder, B.E., Spalding, D.B., 1974. The numerical computation of turbulent flows. Comp. Methods Appl. Mech. Eng. 3, 269-289.

Lisi, I., Taramelli, A., Di Risio, M., Cappucci, S., Gabellini, M., 2009. Flushing efficiency of Augusta Harbour (Italy). J. Coast. Res. 56, 841-845.

MacCready, P, Banas, NS, Hickey, BM, Dever, EP, Liu, Y, 2009. A model study of tideand wind-induced mixing in the Columbia River Estuary and plume. Cont. Shelf Res. 29, 278-291.

Milici, B., De Marchis, M., Sardina, G., Napoli, E., 2014. Effects of roughness on particle dynamics in turbulent channel flows: a DNS analysis. J. Fluid Mech. 739, 465-478.

Napoli, E., Armenio, V., De Marchis, M., 2008. The effect of the slope of irregularly distributed roughness elements on turbulent wall-bounded flows. J. Fluid Mech. 613, 385-394.

Nash, J.E., Sutcliffe, J.V., 1970. River flow forecasting through conceptual models part I - a discussion of principles. J. Hydrol. 10 (3), 282-290 〈http://en. wikipedia.org/wiki/Journal_of_Hydrology .

Niedda, M., Greppi, M., 2007. Tidal, seiche and wind dynamics in a small lagoon in the Mediterranean Sea Estuarine. Coast. Shelf Sci. 74, 21-30.

Orecchio, S., Polizzotto, G., 2013. Fractionation of mercury in sediments during draining of Augusta (Italy) coastal area by modified Tessier method. Microchem. J. 110 (2013), 452-457.

Roman, F., Stipcich, G., Armenio, V., Inghilesi, R., Corsini, S., 2010. Large eddy simulation of mixing in coastal areas. Int. J. Heat Fluid Flow 31 (3), 327-341.

Sankaranarayanan, S., 2007. Modeling the tide and wind-induced circulation in Buzzards Bay. Estuar. Coast. Shelf Sci. 73 (3-4), 467-480.

Shulman, I., Wua, C.R., Lewis, J.K., Paduan, J.D., Rosenfeld, L.K., Kindled, J.C., Ramp, S. R., Collins, C.A., 2002. High resolution modeling and data assimilation in the Monterey Bay area. Cont Shelf Res 22 (8), 1129-1151.

Suursaar, U., Kullas, T., Otsmann, M., 2002. A model study of the sea level variations in the Gulf of Riga and the Vainameri. Sea Cont. Shelf Res. 22, 2001-2019.

Svendsen I.A., 2006. Advanced series on ocean engineering: volume 24. In: Philip L.-F. Liu (Ed.), Introduction to Nearshore Hydrodynamics. World Scientific Publishing Co. Pte. Ltd.; Singapore.

Umgiesser, G., Canu, D.M., Cucco, A., Solidoro, C., 2004. A finite element model for the Venice Lagoon. Development, set up, calibration and validation. J. Mar. Syst. $51,123-145$.

Umgiesser, G., Ferrarin, C., Cucco, A, De Pascalis, F., Bellafiore, D., Ghezzo, M., Bajo, M., 2014. Comparative hydrodynamics of 10 Mediterranean lagoons by means of numerical modeling. J. Geophys. Res. 119 (4), 2212-2226.

van Rijn Leo, C., 2011. Principles of Fluid Flow and Surface Waves in Rivers, Estuaries, Seas and Oceans. Aqua Publications, The Netherlands, ISBN: 978-9079755-02-8 〈www.aquapublications.nl〉.

Vethamony, P., Reddy, G.S., Babu, M.T., Desa, E., Sudheesh, K., 2005. Tidal eddies in a semi-enclosed basin: a model study. Mar. Environ. Res. 59, 519-532.

Wu, J., 1982. Wind-stress coefficients over sea surface from breeze to hurricane. J. Geophys. Res. 87, 9704-9706. 